would suggest that we have hitherto in our treatment of squint paid too much attention to the condition of the recti interni and refraction, and not enough to that of the externi and accommodation.

\section{TWO CASES OF DISLOCATION OF THE CLAVICLE.}

By Ammon Coms, M.D., Webb's Mills, Mo.

As dislocation of the clavicle seems to be a rather unusual occurrence, I offer the history of two cases, being the only ones which have come under my observation.

On the 24th day of July last, Mr. J. F. H., of Casco; Me., was riding upon a wagon loaded with $23 \mathrm{cwt}$. of heavy merchandise, when, owing to an obstruction in the road, he was thrown from his seat and fell, face downward, directly in front of one of the forward whecls, which passed over him squarely from shoulder to shoulder. I was sent for to visit him, and found the stornal end of his left clavicle dislocated forwards, and forming a prominent tumos on the tront of the sternum. A neighboring practitioner had been called before me, and had attempted to reduce the dislocation, but without success. Seating the patient in a common "office chair," I brought him fully under the influence of sulphuric ether. I then placed my knee against his spine, and, taking a shoulder in each hand, drew them steadily and forcibly backwards, while an assistant made pressure over the seat of the luxation. The bone slipped into its place. The patient was insensible for scarcely a minute in all, and awoke from a pleasant dream. The bone showed no disposition to become re-luxated, but finding, from a glance at " Hamilton on Dislocations," which I had taken the precaution to bring with me, that all the cases of this dislociation which had fallen under the observation of that skilful surgeon had efther not been reduced or had escaped after reduction, I made " assurance doubly sure" by treating it like a fractured clavicle; with the addition of a compress over the end of tho bone. 'It has kept its place, iii the most satisfactory manner, up to the piesent time.

The other case camo under my observation while a medical officer in the Army of the Potomac, some time during the winter of 1862-3: As the wagoners of the $2 d$ Brigade, 1st Division, 3d Army Corps, were working off the extra' exhilaration derived from an overdose of sutler's whiskcy, by a pleasant game of fisticuffs, one VoL. IV.-No. 23B of them received a sevcre npward blow upon the front of his left slioulder, which at once placed him hors du combal. As none of his companions were in a condition to know whether he was hurt or only drunk, little attention was paid to him that night, but as he was worse the next morning, I was requested to see him. I found the scapular end of his left clavicle dislocated upward and lying upon the acromion process, which it overlapped an inch or more. Drawing the shoulders backwards, and pressing with my thumb upon the dislocated end of the bone, it was quickly reduced, and, on withdrawing my hand, as quickly became dislocated again. This it persisted in doing for a day or two, in spite of bandages, compresses and adhesive straps, much to my annoyance and vexation, and the pain and discomfort of the patient. At length, however, by some complicated harness, which I cannot now describe, I succeeded in tying it down to its place, and the pa. tient in due time recovered with a good shoulder.

\section{aenorts of attedical Sorieties.}

VERMONT MEDICAI, SOOIETX: REPORTED BY THE SECRETARY, J.. C. BUTI.ER, M.D.

The fifty-fifth annual meeting of this Society was held at Montpelier, October 20th and 21st. Dr. J. S. Richmond, of Woodstock, President, occupied the chair. The session was opened with prayer by Rev. Mr. Underwood, of IIardwick. The proceedings of the annual and semi-nnnnal mectings were read hy the Secretary.

Dr. J. N. Stiles, of Windsor, presented a circular from a committee of the American Medical Association, inviting contributions of medical works from this Society, and from individuals, to a National Medical Library now being established at Washington, D. C. The Secretary was instructed to forward such publications as may be in his possession.

Dr. L. C. Butler, of lissex, from a committee appointed at the last annual meeting of the Socioty, read a paper on "the medical, social and civil aspects of intoxication by alcohol," in which he urged the point that since the Legislature of the State liad by a stringent law prohibited the use of intoxicatingliquors for any other purpose than "for medicinal, mechanical, and manufacturing purposes;" it onght to protect those who require those liquors as medicines from 